\title{
Analyzing differences between different types of pro-environmental behaviors: Do attitude intensity and type of knowledge matter?
}

\begin{abstract}
This study explores whether the associations between general environmental attitudes and proenvironmental behaviors are heterogeneous and whether these associations depend on attitude intensity and the specific pro-environmental behavior. The study also examines the association between objective and subjective knowledge and behavior and the relationship with socioeconomic and personal characteristics. Mixed effects logistic regressions were performed using data from a representative nationwide survey of Spanish citizens aged 18 to 90 years $(\mathrm{N}=2,495)$. The results revealed interesting patterns of heterogeneity. First, only curtailment behaviors (separating trash and using street trash cans) were significantly associated with general environmental attitudes. This result was observed only for the highest level of environmental attitudes. Second, whereas subjective knowledge was associated with all pro-environmental behaviors, objective knowledge was only associated with efficiency behavior (using low-energy light bulbs). Finally, men showed lower levels of reported behavior than women for all pro-environmental activities. The policy implications of these findings are discussed.
\end{abstract}

Keywords: Environmental attitudes; Pro-environmental behaviors; Curtailment; Efficiency; Knowledge; Mixed effects logistic regression. 


\section{Introduction}

Many national and international organizations have joined scientific experts in warning of structural environmental issues such as climate change, deforestation, and loss of biodiversity. They have also warned that other problems derived from these issues will become the greatest challenges that humanity will face in the near future (Sarabia-Sanchez and Rodriguez-Sanchez, 2016; Steg and Vlek, 2009). For example, the United Nations has cited environmental degradation as one of the 10 major threats to humanity (United Nations, 2004). The effects could be irreversible if citizens do not change their patterns of consumption because it is widely recognized that most environmental problems are rooted in human behavior (Gifford et al., 2010). The question of whether sustainability is still possible remains under scrutiny (Worldwatch Institute, 2013). This Worldwatch report states that consumerism has become the dominant paradigm around the world. According to the report, consumerism is no longer viable on a planet that is under stress from its population of 7 billion people, which is forecast to reach 10.6 billion by 2050 . The report concludes that humanity's trajectory must be redirected to create an environmentally sustainable civilization.

Because of its impact on the environment, environmental behavior has become a public issue. Research in the social sciences has sought to understand the factors that motivate and predict proenvironmental behaviors (Kalbar et al., 2018; Steg and Vlek, 2009). Before analyzing these key factors, it is crucial to define how pro-environmental behavior is measured. Traditional approaches have presented pro-environmental behavior as a holistic concept. Under these approaches proenvironmental behavior has primarily been analyzed as an aggregate, undifferentiated construct rather than a set of multiple separate behaviors (e.g., Kaiser and Gutscher, 2003; Karp, 1996). However, pro-environmental behavior encompasses a diverse set of specific behaviors. These behaviors can vary widely in terms of their relative financial cost, effort, knowledge, and a host of other factors (Heimlich and Ardoin, 2008). For example, people concerned with climate change may reduce their car usage or may buy cars with low emissions but may not be interested in changing their purchase patterns to reduce the use of chemical substances (Heimlich and Ardoin, 
2008). Accordingly, environmental psychology scholars have called for the study of specific activities instead of aggregated constructs to explain individuals' pro-environmental behavior (Gatersleben et al., 2014; Karlin et al., 2014). In this study, we consider these behavioral differences. We build on previous studies by differentiating between four pro-environmental behaviors with different frequency-cost attributes. These behaviors are separating the trash, using street trash cans, using low-energy light bulbs, and using recycling centers.

Although research has shown that engagement in one pro-environmental behavior does not necessarily spillover to another (Dolnicar and Grün, 2009; Thøgersen and Ölander, 2003), there is also evidence of some consistency in individuals' behavior (Thøgersen, 2004). The question is whether certain factors are common to many types of pro-environmental behaviors or whether the role of these factors in explaining individual's pro-environmental behavior depends on the type of behavior. For example, Gatersleben et al. (2014) have suggested that factors related to values and identities are generally stable factors that transcend specific situations, whereas attitudinal factors are not. However, although Gatersleben et al. (2014) measured attitudes in a specific way (e.g., "What is your attitude towards buying Fair Trade food products?"), values and identity were measured using general scales (e.g., (Dunlap et al., 2000). It therefore remains unclear whether other general variables such as attitude toward the environment are related to people's proenvironmental behaviors. This study explores this idea by examining general environmental attitude and knowledge. Despite being widely used in the literature to explain different types of proenvironmental behaviors, environmental attitude and knowledge have an inconclusive relationship with behavior (Bamberg and Möser, 2007; Heimlich and Ardoin, 2008; Tam and Chan, 2018).

Increasingly, the most widely accepted explanation for the weak attitude-behavior relationship is the mismatch between the measurement specifications for the two variables (Hini et al., 1995). However, a recent study by Casaló and Escario (2018) suggests that attitude intensity plays an important role in the inconsistency of these results. They found that pro-environmental behavior was only associated with strong environmental attitudes and concluded that an association might 
arise depending on the intensity of the environmental attitudes. We take this idea further, proposing that the association between general environmental attitudes and pro-environmental behavior is heterogeneous and depends not only on attitude intensity but also on the pro-environmental behavior itself. The link between environmental knowledge and pro-environmental behavior has also been questioned in the literature (e.g., Kollmuss and Agyeman, 2002). Although the amount of available environmental information has grown exponentially in the last few decades, this increase in information has not always translated into pro-environmental behavior (Paço and Lavrador, 2017). Despite the importance of offering information on environmental problems, merely providing such information does not appear to be sufficient or useful (Kollmuss and Agyeman, 2002), especially when the target public, which is overloaded with information, believes that it does not need any more information campaigns or leaflets. Scholars have therefore noted that effectively identifying the types of knowledge that encourage pro-environmental behavior is necessary for efficient information strategies (Frick et al., 2004). In view of this finding, we distinguish between two types of knowledge: subjective and objective. We analyze their association with the four proenvironmental behaviors listed above. This study explores not only cognitive variables but also personal and socioeconomic characteristics (e.g., sex, age, and educational level) and positive affect. Few studies have examined the link between affective variables and specific proenvironmental behaviors.

This study uses a nationally representative sample of the Spanish population aged 18 to 90 years $(\mathrm{N}=2,495)$. Environmental studies using a representative sample of Spanish citizens are scarce, so this study can help broaden scholars' understanding of pro-environmental behavior.

The rest of the manuscript is structured as follows. Section 2 provides a brief review of the different types of pro-environmental behaviors according to their frequency-cost attributes. This review serves as the basis for our research hypotheses. Section 3 describes the sample, variables, and analysis method. Section 4 presents the results of the analysis. Section 5 concludes with a discussion of the main findings, research limitations, and avenues for further research. 


\section{Background and research hypotheses}

Pro-environmental behavior is a complex concept that refers to "behavior that harms the environment as little as possible, or even benefits the environment” (Steg and Vlek, 2009, p. 309). Research has sought to elaborate further on the complexity of this type of behavior and identify its underlying determinants by distinguishing between two types of pro-environmental behavior based on frequency-cost attributes: frequent, low-cost behaviors (i.e., curtailment behaviors) and infrequent, high-cost behaviors (i.e., efficiency behaviors). However, classifying activities into one of these two categories is difficult (De Nardo et al., 2017; Karlin et al., 2014). Whereas efficiency behaviors are one-off behaviors that entail the purchase of efficient equipment (e.g., investing in energy-saving devices), curtailment behaviors typically involve repeating inconvenient or sacrificial actions that incur no financial cost (e.g., taking shorter showers [(Abrahamse et al., 2005). These two types of behaviors are psychologically different, and the determinants associated with each type may differ (Gardner and Stern, 2002). Efficiency behaviors usually involve cognitive processing prior to the action. In contrast, curtailment behaviors relate to activities that are repeated frequently with less conscious thinking. Relatively little research has focused on identifying the determinants associated with specific pro-environmental behaviors for these two types of behaviors outside the energy conservation domain (Frederiks et al., 2015; Sütterlin et al., 2011).

People's actions are commonly explained as being driven by attitudes based on the evaluation of expected costs and benefits. People supposedly choose the options with the best benefit/cost relationship in terms of considerations such as effort, money, and social approval. In environmental studies, this assumption has been widely used to investigate suitable ways to promote proenvironmental behaviors within the frameworks of the theory of reasoned action (TRA; Ajzen and Fishbein, 1980) and the theory of planned behavior (TPB; Ajzen, 1991). However, some authors (e.g., Heimlich and Ardoin, 2008; Hini et al., 1995; Tam and Chan, 2018) have questioned the relationship between environmental attitudes and pro-environmental behaviors because empirical studies both support (Bissing-Olson et al., 2016; Gao et al., 2017; Rodríguez-Barreiro et al., 2013) 
and refute this relationship (e.g., Heimlich and Ardoin, 2008; Prati et al., 2017). The reasons for this inconsistency include the use of constellations of behaviors and the measurement of general environmental attitudes (Heimlich and Ardoin, 2008).

Regarding the use of constellations of behaviors, computing pro-environmental behavior indices under the assumption that distinct activities occur simultaneously may cause measurement bias. Thus, different individuals may perform some environmental behaviors but neglect others depending on their motivations and interests (Karlin et al., 2014). Scholars have posited that the variation in correlations between attitudes and behavior may be explained by the cost of the behavior in a broad sense (Diekmann and Preisendörfer, 2003). Consequently, environmental attitudes may be stronger predictors of behaviors when these behaviors are relatively easy or inexpensive (low-cost) than when they are more demanding or costly (high-cost).

The attitude-behavior relationship may be weak because of the mismatch between the measurement specifications for the two variables (Hini et al., 1995). Although specific environmental attitudes may effectively predict related pro-environmental behaviors, research has consistently shown that general environmental attitudes alone rarely lead to specific proenvironmental behaviors (Gifford and Sussman, 2012). A recent study explored whether the association between general environmental attitudes and pro-environmental behavior is heterogeneous or, more specifically, whether the existence of this association depends on the intensity of environmental attitudes (Casaló and Escario, 2018). The study found that proenvironmental behavior is only associated with strong environmental attitudes such as those that arise when people believe that the environment should be protected even if doing so is expensive. Although this line of research seems promising, the study used an aggregate measure of proenvironmental behavior. As suggested by the curtailment versus efficiency framework, it may be of interest to study whether this heterogeneous pattern is observed for specific behaviors that involve different frequency or cost perceptions. Thus, we propose the following hypotheses: 
H1: The associations between general environmental attitudes and pro-environmental behaviors depend on the specific behavior.

H2: The associations between general environmental attitudes and pro-environmental behaviors depend on attitude intensity.

Environmental knowledge is another psychological factor that is extensively used in the literature to explain pro-environmental behavior. The common assumption is that, without knowledge about environmental issues, an individual is unlikely to knowingly be concerned about the environment and to deliberately act in pro-environmental ways (Gifford and Nilsson, 2014; Meinhold and Malkus, 2005). Therefore, environmental knowledge is commonly viewed as a precondition to volitional action (Frick et al., 2004). However, although knowledge theoretically seems to play a significant role in pro-environmental behavior, the empirical evidence is inconclusive, as shown by several meta-analyses (e.g., Bamberg and Möser, 2007; Hines et al., 1987; Kollmuss and Agyeman, 2002). Environmental knowledge is therefore considered a necessary but not sufficient condition for an individual's pro-environmental behavior (Kollmuss and Agyeman, 2002). Researchers have broadly distinguished between subjective (or self-reported) knowledge (i.e., people's perceived knowledge), actual (or objective) knowledge (i.e., what people actually know), and personal experience (Ellen, 1994). Research has shown that subjective and objective knowledge are often weakly correlated, mainly because people rarely accurately perceive how good their factual knowledge is (Aertsens et al., 2011). Empirical studies have shown that subjective knowledge has a more significant influence on people's pro-environmental behavior than objective knowledge does (Bamberg and Möser, 2007; Ellen, 1994). In others words, the more people think they know about the environment, the more likely they are to act.

However, most scales for measuring environmental knowledge are based on either objective or subjective knowledge, which might explain the contradictory results found in the literature (Vicente-Molina et al., 2013). It is therefore necessary to distinguish between these two types of 
knowledge and identify which is related to pro-environmental behaviors. Thus, we propose the following hypotheses:

H3: Greater subjective knowledge about environmental issues is positively associated with all proenvironmental behaviors considered in this study.

H4: Greater objective knowledge about environmental issues is positively associated with all proenvironmental behaviors considered in this study.

For completeness, the possible association between personal and socioeconomic characteristics with pro-environmental behaviors should also be considered. First, the literature presents gender as a key predictor of pro-environmental behavior. There is considerable evidence that women behave more pro-environmentally than men (Arnocky and Stroink, 2011; Bamberg and Möser, 2007; Casaló and Escario, 2018; Collado et al., 2017a; Gifford and Nilsson, 2014). Differences between men and women may be explained by personality traits, roles, and socialization (Casaló and Escario, 2016; Duarte et al., 2017; Zelezny et al., 2000). Women are influenced by socialization to exhibit a stronger care ethic, to be more socially responsible, and to show more empathy. These characteristics make women act more pro-environmentally than men (Arnocky and Stroink, 2011). Second, age is a key predictor of pro-environmental behavior. Younger people behave less proenvironmentally than older people (Arnocky and Stroink, 2011; Bamberg and Möser, 2007; Casaló and Escario, 2018; Gifford and Nilsson, 2014), perhaps because older people are more motivated to improve the quality of the environment for the next generation (Shen and Saijo, 2008). Younger people usually perceive less urgency to behave pro-environmentally because they believe that technological advances will address future environmental problems (Benn, 2004). Third, education level and employment status (as a proxy for income) have also been identified as positive predictors of pro-environmental behaviors (Casaló and Escario, 2018). Some results suggest that this relationship depends on the specific behavior because people may not have the intention to embrace less convenient pro-environmental behaviors. For example, more affluent people have greater access to private cars, reducing their use of public transport (Rodríguez-Barreiro et al., 2013). 
Finally, behaviors may also depend on the individual's emotional state and affective responses (Belanche et al., 2013). The literature suggests that emotions and positive affect may drive proenvironmental behaviors (e.g., Vining and Ebreo, 2002; Bissing-Olson et al., 2013) and the desire to engage in pro-environmental action (e.g., Carrus et al., 2008). However, instead of considering general emotions and positive affect, studies have predominantly analyzed the influence of individual positive and negative emotions related to specific topics such as introducing a new water charge (Rodriguez-Sanchez et al., 2018) or engaging in different pro-environmental behaviors (Bissing-Olson et al., 2016; Carrus et al., 2008). This study focuses on happiness. Happiness refers to a predominance of positive over negative affect and a satisfaction with life as a whole. It is a crucial motivator for human behaviors (Lu et al., 2001). Whereas sad people are more doubtful when deciding whether to perform a behavior, happier individuals are more confident and may find it easier to decide to perform a behavior (Belanche et al., 2013). This reasoning is consistent with recent results in the organizational context, where positive affect as a general feeling has been found to influence employees' pro-environmental behavior in the workplace (Bissing-Olson et al., 2013). Gender, age, education level, employment status, and happiness are included in our research model. Thus, we propose the following hypotheses:

H5: Sex is associated with all pro-environmental behaviors considered in this study.

H6: Age is positively associated with all pro-environmental behaviors considered in this study. H7: The associations between education level and pro-environmental behaviors depend on the specific behavior.

H8: The associations between employment status and pro-environmental behaviors depend on the specific behavior.

H9: Happiness is positively associated with all pro-environmental behaviors considered in this study.

Figure 1 illustrates our research model. 


\section{Method}

\subsection{Sample}

We tested our research hypotheses using data from the "December 2015 Public Opinion Barometer" carried out by the Spanish Center of Sociological Research (Centro de Investigaciones Sociológicas, CIS). The CIS uses rigorous statistical procedures to obtain representative samples. This survey is based on a nationally representative sample of Spanish people aged 18 to 90 years. Interviews are conducted in respondents' homes to gather the data. All responses are anonymous and are protected by data protection laws. A total of 2,495 persons participated in this edition of the survey. The sampling error was $\pm 2 \%$ at the $95.5 \%$ confidence level. The survey was conducted between October 1 and 12, 2015.

\subsection{Variables}

\subsubsection{Pro-environmental behavior}

The dependent variables used in this study were four dichotomous variables indicating whether the respondent regularly performed four pro-environmental friendly behaviors $(1=$ yes, $0=$ otherwise). The four variables resulted from responses to the following four questions: 1) "Do you regularly use street trash cans to deposit waste?"; 2) "Do you regularly separate domestic trash by type of waste (organic, plastic, and paper)?”; 3) "Do you regularly use low-energy light bulbs in your home?"; 4) "Do you regularly use household waste recycling centers or call your city council to dispose of electrical appliances that are no longer useful?" These activities can be categorized as efficiency or curtailment behaviors according to the definitions established earlier. Thus, using street trash cans and separating trash are curtailment behaviors (frequent, low-cost activities), whereas using low-energy light bulbs is an efficiency behavior because it entails a financial cost and is performed infrequently. However, the use of a recycling center cannot easily be placed into one of these two categories. It could be classified differently depending on the interpretation of these categories. Following De Nardo et al. (2017), we considered it a neutral behavior because it is not performed frequently but, depending on certain personal factors (e.g., distance from the waste 
recycling center), it could be considered a high-cost behavior.

\subsubsection{Environmental attitude}

The focus of the study was to explore the association between general environmental attitudes and pro-environmental behaviors. For this purpose, three dichotomous variables were used to measure the intensity of environmental attitudes. Respondents completed the statement "The environment should be protected ..." with one of the following options: "a) but it must not involve additional costs for citizens; b) whenever the required measures are not too expensive; or c) although this protection sometimes entails high costs." The first variable, Low environmental attitudes, took the value 1 if the respondent chose response (a), and 0 otherwise. This variable was the reference category. The second variable, Moderate environmental attitudes, took the value 1 if the respondent chose response (b), and 0 otherwise. Finally, the third variable, High environmental attitudes, took the value 1 if the respondent chose response (c), and 0 otherwise.

\subsubsection{Knowledge}

We computed several variables to measure the respondent's knowledge about environmental issues. These variables captured two types of knowledge: subjective and objective (Ellen, 1994). The first four variables captured subjective knowledge. Participants responded to the following question: "Do you consider yourself not informed at all, poorly informed, quite well informed, and very well informed about environmental issues?" The corresponding dichotomous variables were Not informed, Poorly informed, Quite well informed, and Very well informed depending on the response. The last variable was taken as the reference category. Objective knowledge was measured by asking respondents whether they had heard of the 2015 Paris Climate Change Conference. This measure was consistent with the definition of objective knowledge used by Brucks (1986) and (Ellen, 1994). Thus, objective knowledge was defined as declarative knowledge about concepts, objects, and events, including specific verbal and non-verbal symbols.

\subsubsection{Personal and socioeconomic variables}

Personal and socioeconomic characteristics were also included in the analyses. We considered 
two physical characteristics. We used a dichotomous variable, Male, to record gender $(1=$ male, $0=$ female), and eight dichotomous variables, Age10 to Age80, to measure whether the respondents were in their teens, twenties, and so on. Age10 was the reference category.

Several socioeconomic characteristics were considered. We used High school $(1=$ if the respondent had completed high school or vocational training, $0=$ otherwise $)$ and University $(1=$ if the respondent had a university degree, $0=$ otherwise) to measure the respondents' education level. We used Unemployed $(1=$ yes, $0=$ otherwise $)$, Student $(1=$ yes, $0=$ otherwise $)$, and Retired $(1=$ yes, $0=$ otherwise) to measure respondents' employment status. The set of covariates also included Happiness, which was measured using an index variable to assess whether respondents perceived themselves as happy (general positive affect) on a scale ranging from 0 (completely unhappy) to 10 (completely happy).

\subsection{Analyses}

We tested the associations proposed in our hypotheses using multilevel or mixed effects logistic regressions. This kind of regression is an extension of standard logistic regression. It accounts for the fact that individuals are nested within groups. Therefore, multilevel regression accounts for the fact that responses from individuals in the same group may be more similar than what could be expected by randomness and that, consequently, responses may be more strongly correlated within groups. In this study, individuals were clustered according to region (Spain comprises 19 regions). People in the same region have a similar natural environment, a similar quality of environment, similar experiences with nature, similar regional policies, similar regional media handling of environmental issues, and so on. Because responses are more similar within clusters, the assumption of independent observations would not be valid and estimated standard errors would be biased toward zero. To deal with this correlation among clusters (i.e., regions), mixed effects logistic regressions with a random intercept for each region were estimated.

Scholars have found that model fit can be significantly enhanced by incorporating mixed effects in logistic regressions (Chi and Voss, 2005; Li et al., 2019). The mixed effects approach has 
increasingly been incorporated into environmental studies (e.g., Boeve-de Pauw and van Petegem, 2010; Casaló and Escario, 2018, 2016; Li et al., 2019). Finally, an attractive feature of mixed effects logistic regression is that it nests standard logistic regression as a particular case. Consequently, the likelihood ratio (LR) can be used to test which approach performs better. All analyses were carried out using R statistical software (version 3.4.3).

\section{Results}

Table 1 shows the mean and other descriptive statistics for the dependent variables. The most prevalent pro-environmental behavior was using street trash cans. This behavior was performed regularly by $78.4 \%$ of respondents. The least prevalent behavior (70.5\% of respondents) was regularly using low-energy light bulbs. Table 2 shows the descriptive data for attitudes and subjective and objective knowledge. Approximately $50 \%$ of the sample had strong environmental attitudes. Although participants mainly reported that they were poorly informed or quite well informed about environmental issues (subjective knowledge), most reported that they had heard of the 2015 Paris Climate Change Conference (objective knowledge).

\section{TABLE 1 ABOUT HERE}

\section{TABLE 2 ABOUT HERE}

Estimates for the mixed effects logistic regressions are reported in Table 3. With the exception of the estimates for the use of low-energy light bulbs, the results of the LR test led to the rejection of the logistic regression model in favor of the mixed effects logistic regression model. The random intercept variance at the regional level was significant at the $95 \%$ level, indicating heterogeneity across regions. The model fit, measured using the R-squared value, was enhanced by including random intercepts for the four environmental behaviors. Even though R-squared values are not very high, these values are in general above 0.2, which is considered as adequate (McFadden, 1977). Environmental attitudes were associated with regularly using trash cans and regularly separating domestic trash (curtailment behaviors). However, there were no significant associations between environmental attitudes and regularly using low-energy light bulbs (efficiency behavior) or 
regularly using recycling centers for electrical appliances (neutral behavior). These results provide evidence to support hypothesis H1. Attitudes seem to be positively related to frequent, low-cost behaviors (i.e., curtailment behaviors). Even for behaviors where a significant association was found, the association was only significant for the strongest environmental attitudes (i.e., when respondents considered that the environment should be protected even if it entails a high cost for citizens). These empirical results support hypothesis $\mathrm{H} 2$ for curtailment behaviors.

\section{TABLE 3 ABOUT HERE}

Regarding hypothesis H3, which posits an association between subjective knowledge and proenvironmental behaviors, our results were robust. Being well informed was positively associated with the four pro-environmental behaviors. Being quite well informed was positively associated with all pro-environmental behaviors, except the use of low-energy light bulbs. The magnitudes of the coefficients increased as did respondents' perceived knowledge about environmental issues. Therefore, hypothesis H3 is supported. In contrast, regarding the association with objective knowledge (H4), having heard of the 2015 Paris Climate Change Conference was only significantly associated with regularly using low-energy light bulbs. Therefore, hypothesis H4 is only partially supported. However, objective knowledge was associated with the efficiency behavior considered.

We investigated the role of personal and sociodemographic variables. Estimates provided a negative coefficient for the Male variable in all four columns of Table 3. All four coefficients were significant, except the coefficient for using street trash cans. These results partially support hypothesis H5. Being male seems to be associated with lower levels of pro-environmental behaviors. Older people appear to be more involved in pro-environmental behavior, except using low-energy light bulbs. These results partially support hypothesis H6. People aged 40 years or older were observed to recycle more than younger people. The results for education level were more robust. The estimates showed that completing high school and holding a university degree were positively associated with all pro-environmental behaviors. The exception was separating trash, which was significantly associated only with having a university degree. The results thus fail to 
support hypothesis $\mathrm{H} 7$, which posits that the association between education and pro-environmental behaviors depends on the specific behavior. The relationship between employment status and proenvironmental behaviors seems to depend on the specific behavior. We observed that, once the effect of the remaining variables had been accounted for, retired respondents separated the trash and used recycling centers less than other respondents. Thus, hypothesis H8 is supported. Despite not being significant in most cases, the coefficients for employment status were negative, indicating that respondents in employment (reference category) reported greater pro-environmental behaviors. Finally, happiness was positively associated with all pro-environmental behaviors. These results support hypothesis $\mathrm{H} 9$.

\section{Discussion}

We used a national representative sample of Spanish residents to test the associations between general environmental attitudes and four pro-environmental behaviors. These behaviors were classified according to their frequency-cost attributes. As in recent studies (Casaló and Escario, 2018), we evaluated whether these associations depended on the intensity of respondents' general environmental attitudes. We also examined the associations between objective and subjective knowledge and these four pro-environmental behaviors. Lastly, we explored the possible relationship with several socioeconomic and personal characteristics and with positive affect.

As stated earlier, pro-environmental behaviors can be separated into curtailment and efficiency behaviors. These two categories involve different constraints and motivations for performing the behavior (Gardner and Stern, 2002; Stern, 2011). Our findings support this idea, revealing different patterns of association between the independent variables under study and specific proenvironmental behaviors. Whereas using street trash cans and separating trash (i.e., curtailment behaviors) were associated with environmental attitudes, using low-energy light bulbs (i.e., efficiency behavior) and using recycling centers (i.e., neutral behavior) were not. This finding is consistent with previous studies showing that positive environmental attitudes influence low-cost behaviors more than high-cost behaviors (Diekmann and Preisendörfer, 2003; Fielding et al., 2010). 
A likely explanation is the low-cost hypothesis, which states that the lower the cost pressure is in a given situation, the easier it is for actors to transform attitudes into behavior (Diekmann and Preisendörfer, 2003). However, for efficiency behaviors, several factors, especially financial incentives, may outweigh attitudes because such behaviors usually require active participation and financial investment (Garcia-Cuerva et al., 2016). This idea was expressed by Von Borgstede et al. (2013) as "I know that I ought to do it, but it is still too costly or time-consuming for me" (p. 184). Consistent with the findings of Casaló and Escario's (2018) study, these results indicate that the association between environmental attitudes and curtailment behaviors is heterogeneous. More specifically, the significance of the association depends on the intensity of the individual's attitudes. This result is consistent with the TPB model, which posits that individuals take actions (in this case, pro-environmental behaviors) if the benefits outweigh the costs. Thus, a stronger attitude may reflect higher perceived benefits of acting pro-environmentally. Consequently, a stronger attitude may imply a higher likelihood of compensating for the costs of pro-environmental behavior (Casaló and Escario, 2018). The benefits and costs evaluated by individuals refer to benefits and costs in terms of money, effort, social image, breaking the norms, and so on. Therefore, our findings imply that any actions by policymakers (e.g., communication campaigns) should stress the benefits of behaving pro-environmentally to ensure that people accept the high costs of such behaviors (Casaló and Escario, 2018). If citizens perceive that expected benefits are high (Zeithaml, 1988), they may be encouraged to engage in pro-environmental behaviors, even if these behaviors entail high costs.

Our results also show that respondents have low perceptions of their knowledge about environmental issues. As previous studies have shown, lay people generally do not consider themselves knowledgeable about environmental matters (Pagiaslis and Krontalis, 2014). The fact that most respondents had heard of the 2015 Paris Climate Change Conference was unexpected because respondents normally display fairly poor knowledge when asked about specific environmental issues (Vicente-Molina et al., 2013). Consistent with this finding, some scholars (e.g., Robelia and Murphy, 2012) have reported good knowledge about specific environmental 
problems (e.g., where garbage goes) but poor knowledge about others (e.g., water quality). We nonetheless believe that this result owes to the extensive media coverage of this conference during the data collection period in Spain. Our analyses provided interesting results regarding the relationship between the two types of knowledge (subjective and objective) and pro-environmental behaviors. The differences in the results for the two types of knowledge seem to highlight the need to distinguish between these types of knowledge in environmental studies. This finding supports claims by other authors (e.g., Carmi et al., 2015; Pieniak et al., 2010). Our findings suggest that subjective knowledge is more strongly associated with pro-environmental behaviors than objective knowledge is. This finding is consistent with those reported in previous studies (Aertsens et al., 2011; Ellen, 1994; Vicente-Molina et al., 2013). The relationship between objective knowledge and behavior was only significant for the use of low-energy light bulbs (i.e., efficiency behavior). A possible explanation for this result is that efficiency behaviors usually require greater information processing because they are performed occasionally rather than as part of a routine (Boudet et al., 2016). Further research on a greater number of efficiency behaviors is needed to shed light on this matter. Like other scholars before us (e.g., Fielding and Head, 2012; Pothitou et al., 2016), we found a direct relationship between subjective knowledge and different pro-environmental behaviors. This relationship nonetheless differed for different behaviors. For curtailment and neutral behaviors, having moderate perceived knowledge was associated with pro-environmental behavior. In contrast, for the efficiency behavior, this relationship was only significant for individuals with good perceived knowledge. This finding can help corroborate the assumption that efficiency behaviors require a large amount of knowledge and information. Finally, research supports the hypothesis that self-reported knowledge is a necessary component of environmental action (Robelia and Murphy, 2012) because having better subjective knowledge makes individuals more likely to engage in pro-environmental behavior. Our results corroborate this hypothesis regardless of the type of behavior (i.e., curtailment or efficiency). Therefore, as recently proposed by other scholars (e.g., Casaló and Escario, 2018; Collado et al., 2017b), it may be wise to develop education programs that 
enhance citizens' knowledge about environmental issues so that citizens can benefit from this greater knowledge.

Our results regarding sociodemographic and personal characteristics are consistent with those reported in the literature. Women exhibited higher levels of pro-environmental behaviors (Arnocky and Stroink, 2011; Bamberg and Möser, 2007; Collado et al., 2017a; Gifford and Nilsson, 2014), older people appeared to be more involved in pro-environmental behaviors (Arnocky and Stroink, 2011; Bamberg and Möser, 2007; Collado et al., 2017a; Gifford and Nilsson, 2014), and education was positively associated with all pro-environmental behaviors (Casaló and Escario, 2018). These results suggest that greater efforts must be made for certain citizens (i.e., men, young people, and those with lower education levels) and that campaigns (e.g., education programs) should be adapted to target those individuals. These actions might prove effective because men seem more receptive than women to environmental programs (Vicente-Molina et al., 2018), and young and less-educated individuals might be more easily influenced because their beliefs are less stable (Belanche et al., 2012). However, our results suggest that the influence of these variables might depend on the specific behavior. For example, age was not associated with the use of low-energy light bulbs, which was the least frequent behavior among those behaviors considered in this study. This result may be explained by the fact that frequent, low-cost pro-environmental behaviors may become automatic and may be performed instinctively. These behaviors are executed repeatedly and may therefore be routinized, eventually becoming a habit (Aarts et al., 1998). Research has suggested that people might develop an increasing preference for routinization as they grow older (Bouisson, 2002). Accordingly, the elderly usually perform more routine behaviors than young people. We also observed that employment status was related to some pro-environmental behaviors but not others. This finding may help explain previous proposals in the literature. Education and employment status are commonly used as proxies for income (e.g., Casaló and Escario, 2018). Also, our results suggest that the influence of education is fairly stable across behaviors. Therefore, the heterogeneous influence of income on pro-environmental behaviors suggested in the literature 
(Rodríguez-Barreiro et al., 2013) may arise not only because of specific behavior but also because of employment status. Finally, building on previous studies, this study also indicates that happiness is positively associated with all pro-environmental behaviors. This finding confirms that individual behaviors may also depend on emotional states and affective responses (Belanche et al., 2013). The fact that sad people are more doubtful and happier individuals are more confident may influence decisions to perform a given behavior (Belanche et al., 2013).

Although this study provides initial evidence of the role of attitude intensity and the type of environmental knowledge, as well as the importance of studying specific environmental behaviors, it has several limitations. These limitations can provide avenues for further research. First, although we used a large nationally representative sample of Spanish citizens aged 18 to 90 years, caution should be exercised when interpreting these results in a wider context. This study was conducted using data on only one country. Therefore, the results may not be generalizable to other contexts. Future research should clarify whether these results may be generalized to other countries and contexts. Second, we used cross-sectional survey data. Therefore, future studies should use longitudinal data to clarify the causal influences between the variables considered in this research. Third, the data were collected from a survey by the CIS ("December 2015 Public Opinion Barometer"). Thus, the scales used to measure the variables in this research were not developed for the purposes of our study. We did not participate in the development of appropriate measurement scales. The measurement of pro-environmental behaviors relies on self-reported measures. Even though this measurement is common in behavioral research, answers may be inflated as respondents may be keen to show their green credentials (Barr, 2007). In future research, it would be wise to focus on more objective measures of pro-environmental behaviors. Finally, we considered specific behaviors related to recycling and energy conservation. These behaviors are categorized as either efficiency or curtailment behaviors. In reality, however, it is difficult to find recycling behaviors that can be categorized as efficiency behaviors. For example, the use of recycling centers cannot 
easily be placed into one of these two categories. Future studies could analyze other efficiency and curtailment behaviors considering other environmental domains.

This study contributes to the literature by differentiating between curtailment, neutral, and efficiency behaviors according to their frequency-cost attributes and by examining their relationships with environmental attitudes, subjective and objective knowledge, socioeconomic and personal characteristics, and positive affect. Our findings reveal different associations between these variables and specific pro-environmental behaviors. Environmental attitudes are only associated with curtailment behaviors. These associations are heterogeneous. Their significance depends on attitude intensity. Regarding the associations with subjective and objective knowledge and socioeconomic and personal characteristics, our results are consistent with the literature. The final contribution of this study is to show that happiness is positively associated with all proenvironmental behaviors.

\section{References}

Aarts, H., Verplanken, B., Van Knippenber, A., 1998. Predicting behavior from actions in the past: Repeated decision making or a matter of habit? J. Appl. Soc. Psychol. 28, 1355-1374. https://doi.org/10.1111/j.1559-1816.1998.tb01681.x

Abrahamse, W., Steg, L., Vlek, C., Rothengatter, T., 2005. A review of intervention studies aimed at household energy conservation. J. Environ. Psychol. 25, 273-291. https://doi.org/10.1016/j.jenvp.2005.08.002

Aertsens, J., Mondelaers, K., Verbeke, W., Buysse, J., van Huylenbroeck, G., 2011. The influence of subjective and objective knowledge on attitude, motivations and consumption of organic food. Br. Food J. 113, 1353-1378. https://doi.org/10.1108/00070701111179988

Ajzen, I., 1991. The theory of planned behavior. Organ. Behav. Hum. Decis. Process. 50, 179-211. https://doi.org/10.1016/0749-5978(91)90020-T

Ajzen, I., Fishbein, M., 1980. Understanding attitudes and predicting social behaviour. PrenticeHall, Englewood Cliffs, New Jersey.

Arnocky, S., Stroink, M., 2011. Gender differences in environmentalism: The mediating role of emotional empathy. Curr. Res. Soc. Psychol. 16, 1-14.

Bamberg, S., Möser, G., 2007. Twenty years after Hines, Hungerford, and Tomera: A new metaanalysis of psycho-social determinants of pro-environmental behaviour. J. Environ. Psychol. 27, 14-25. https://doi.org/10.1016/j.jenvp.2006.12.002

Barr, S., 2007. Factors influencing environmental attitudes and behaviors. Environ. Behav. 39, 435473. https://doi.org/10.1177/0013916505283421

Belanche, D., Casaló, L., Flavián, C., 2012. Understanding the influence of social information sources on e-government adoption. Inf. Res. 17, 1-28. 
Belanche, D., Casaló, L. V., Guinalíu, M., 2013. The role of consumer happiness in relationship marketing. J. Relatsh. Mark. 12, 79-94. https://doi.org/10.1080/15332667.2013.794099

Benn, J., 2004. Consumer education between "consumership" and citizenship: Experiences from studies of young people. Int. J. Consum. Stud. 28, 108-116. https://doi.org/10.1111/j.14706431.2003.00364.x

Bissing-Olson, M.J., Fielding, K.S., Iyer, A., 2016. Experiences of pride, not guilt, predict proenvironmental behavior when pro-environmental descriptive norms are more positive. J. Environ. Psychol. 45, 145-153. https://doi.org/10.1016/j.jenvp.2016.01.001

Bissing-Olson, M.J., Iyer, A., Fielding, K.S., Zacher, H., 2013. Relationships between daily affect and pro-environmental behavior at work: The moderating role of pro-environmental attitude. J. Organ. Behav. 34, 156-175. https://doi.org/10.1002/job.1788

Boeve-de Pauw, J., van Petegem, P., 2010. A cross-national perspective on youth environmental attitudes. Environmentalist 30, 133-144. https://doi.org/10.1007/s10669-009-9253-1

Boudet, H.S., Flora, J.A., Armel, K.C., 2016. Clustering household energy-saving behaviours by behavioural attribute. Energy Policy 92, 444-454. https://doi.org/10.1016/j.enpol.2016.02.033

Bouisson, J., 2002. Routinization preferences, anxiety, and depression in an elderly French sample. J. Aging Stud. 16, 295-302. https://doi.org/10.1016/S0890-4065(02)00051-8

Brucks, M., 1986. A typology of consumer knowledge content. NA - Adv. Consum. Res. 13, 58-63.

Carmi, N., Arnon, S., Orion, N., 2015. Transforming environmental knowledge into behavior: The mediating role of environmental emotions. J. Environ. Educ. 46, 183-201. https://doi.org/10.1080/00958964.2015.1028517

Carrus, G., Passafaro, P., Bonnes, M., 2008. Emotions, habits and rational choices in ecological behaviours: The case of recycling and use of public transportation. J. Environ. Psychol. 28, 51-62. https://doi.org/10.1016/j.jenvp.2007.09.003

Casaló, L.V., Escario, J.J., 2018. Heterogeneity in the association between environmental attitudes and pro-environmental behavior: A multilevel regression approach. J. Clean. Prod. 175, 155163. https://doi.org/10.1016/j.jclepro.2017.11.237

Casaló, L. V., Escario, J.J., 2016. Intergenerational association of environmental concern: Evidence of parents' and children's concern. J. Environ. Psychol. 48, 65-74. https://doi.org/10.1016/j.jenvp.2016.09.001

Chi, G., Voss, P., 2005. Migration decision-making: A hierarchical regression approach. J. Reg. Anal. Policy 35, 11-22. https://doi.org/10.3109/09593985.2012.666632

Collado, S., Evans, G.W., Sorrel, M.A., 2017a. The role of parents and best friends in children's pro-environmentalism: Differences according to age and gender. J. Environ. Psychol. 54, 27 37. https://doi.org/10.1016/j.jenvp.2017.09.007

Collado, S., Staats, H., Corraliza, J.A., Hartig, T., 2017b. Restorative environments and health, in: Navarro, O., Fleury-Bahi, G., Pol, E. (Eds.), Handbook of Environmental Psychology and Quality of Life Research. Springer, New York, pp. 127-148. https://doi.org/10.1007/978-3319-31416-7_7

De Nardo, M., Brooks, J.S., Klinsky, S., Wilson, C., 2017. Social signals and sustainability: ambiguity about motivations can affect status perceptions of efficiency and curtailment behaviors. Environ. Syst. Decis. 37, 184-197. https://doi.org/10.1007/s10669-017-9624-y

Diekmann, A., Preisendörfer, P., 2003. Green and greenback. Ration. Soc. 15, 441-472. https://doi.org/10.1177/1043463103154002

Dolnicar, S., Grün, B., 2009. Environmentally Friendly Behavior: Can Heterogeneity Among Individuals and Contexts/ Environments Be Harvested for Improved Sustainable Management? 
Environ. Behav. 41, 693-714. https://doi.org/10.1177/0013916508319448

Duarte, R., Escario, J.J., Sanagustín, M.V., 2017. The influence of the family, the school, and the group on the environmental attitudes of European students. Environ. Educ. Res. 23, 23-42. https://doi.org/10.1080/13504622.2015.1074660

Dunlap, R.E., Van Liere, K.D., Mertig, A.G., Jones, R.E., 2000. New Trends in Measuring Environmental Attitudes: Measuring Endorsement of the New Ecological Paradigm: A Revised NEP Scale. J. Soc. Issues 56, 425-442. https://doi.org/10.1111/0022-4537.00176

Ellen, P.S., 1994. Do we know what we need to know? Objective and subjective knowledge effects on pro-ecological behaviors. J. Bus. Res. 30, 43-52. https://doi.org/10.1016/01482963(94)90067-1

Fielding, K.S., Head, B.W., 2012. Determinants of young Australians' environmental actions:The role of responsibility attributions, locus of control, knowledge and attitudes. Environ. Educ. Res. 18, 171-186. https://doi.org/10.1080/13504622.2011.592936

Fielding, K.S., Thompson, A., Louis, W.R., Warren, C., 2010. Environmental sustainability: Understanding the attitudes and behaviour of Australian households, AHURI Final Report.

Frederiks, E.R., Stenner, K., Hobman, E. V., 2015. The socio-demographic and psychological predictors of residential energy consumption: A comprehensive review. Energies 8, 573-609. https://doi.org/10.3390/en8010573

Frick, J., Kaiser, F.G., Wilson, M., 2004. Environmental knowledge and conservation behavior: Exploring prevalence and structure in a representative sample. Pers. Individ. Dif. 37, 15971613. https://doi.org/10.1016/j.paid.2004.02.015

Gao, L., Wang, S., Li, J., Li, H., 2017. Application of the extended theory of planned behavior to understand individual's energy saving behavior in workplaces. Resour. Conserv. Recycl. 127, 107-113. https://doi.org/10.1016/j.resconrec.2017.08.030

Gardner, G.T., Stern, P.C., 2002. Environmental problems and human behavior, 2nd ed. Pearson Custom Publishing, Boston.

Gatersleben, B., Murtagh, N., Abrahamse, W., 2014. Values, identity and pro-environmental behaviour. Contemp. Soc. Sci. 9, 374-392. https://doi.org/10.1080/21582041.2012.682086

Gifford, R., Nilsson, A., 2014. Personal and social factors that influence pro-environmental concern and behaviour: A review. Int. J. Psychol. 49, 141-157. https://doi.org/10.1002/ijop.12034

Gifford, R., Steg, L., Reser, J.P., Martin, P.R., Cheung, F.M., Knowles, M.C., Kyrios, M., Littlefield, L., Overmier, J.B., Prieto, J.M., 2010. Environmental Psychology, in: MartinIAAP Handbook of Applied Psychology .

Gifford, R., Sussman, R., 2012. The Oxford handbook of environmental and conservation psychology, in: S.D., C., Nathan, P.E. (Eds.), . Oxford University Press, Oxford, UK.

Heimlich, J., Ardoin, N., 2008. Understanding behavior to understand behavior change: A literature review. Environ. Educ. Res. 14, 215-237. https://doi.org/10.1080/13504620802148881

Heimlich, J.E., Ardoin, N.M., 2008. Understanding behavior to understand behavior change: a literature review. Environ. Educ. Res. 14, 215-237. https://doi.org/10.1080/13504620802148881

Hines, J.M., Hungerford, H.R., Tomera, A.N., 1987. Analysis and synthesis of research on responsible environmental behavior: A meta-analyis. J. Environ. Educ. 18, 1-8.

Hini, D., Gendall, P., Kearns, Z., 1995. The link between environmental attitudes and behavior. Mark. Bull. 6, 22-31.

Kaiser, F.G., Gutscher, H., 2003. The proposition of a general version of the theory of planned behavior: Predicting ecological behavior. J. Appl. Soc. Psychol. 33, 586-603. 
https://doi.org/10.1111/j.1559-1816.2003.tb01914.x

Karlin, B., Davis, N., Sanguinetti, A., Gamble, K., Kirkby, D., Stokols, D., 2014. Dimensions of conservation: exploring differences among energy behaviors. Environ. Behav. 46, 423-452. https://doi.org/10.1177/0013916512467532

Karp, D.G., 1996. Values and their effect on pro-environmental behavior. Environ. Behav. 28, 111133. https://doi.org/10.1177/0013916596281006

Kollmuss, A., Agyeman, J., 2002. Mind the gap: Why do people behave environmentally and what are the barriers to pro-environmental behaviour. Environ. Educ. Res. 8, 239-260. https://doi.org/10.1080/1350462022014540

Li, D., Li, C., Miwa, T., Morikawa, T., 2019. An Exploration of Factors Affecting Drivers' Daily Fuel Consumption Efficiencies Considering Multi-Level Random Effects. Sustainability 11, 393. https://doi.org/10.3390/su11020393

Lu, L., Gilmour, R., Kao, S., Weng, T., 2001. Two ways to achieve happiness. Pers. Individ. Dif. 30, 1161-1174.

McFadden, D., 1977. Quantitative Methods for Analyzing Travel Behaviour of Individuals: Some Recent Developments (No. 474), Cowles Foundation Discussion Papers. Cowles Foundation for Research in Economics, Yale University, New Haven.

Meinhold, J.L., Malkus, A.J., 2005. Adolescent environmental behaviors: Can knowledge, attitudes and self-efficacy make a difference? Environ. Behav. 37, 511-532. https://doi.org/10.1177/0013916504269665

Paço, A., Lavrador, T., 2017. Environmental knowledge and attitudes and behaviours towards energy consumption. J. Environ. Manage. 197, 384-392. https://doi.org/10.1016/j.jenvman.2017.03.100

Pagiaslis, A., Krontalis, A.K., 2014. Green consumption behavior antecedents: Environmental concern, knowledge, and beliefs. Psychol. Mark. 31, 335-348. https://doi.org/10.1002/mar.20698

Pieniak, Z., Aertsens, J., Verbeke, W., 2010. Subjective and objective knowledge as determinants of organic vegetables consumption. Food Qual. Prefer. 21, 581-588.

https://doi.org/10.1016/j.foodqual.2010.03.004

Pothitou, M., Hanna, R.F., Chalvatzis, K.J., 2016. Environmental knowledge, pro-environmental behaviour and energy savings in households: An empirical study. Appl. Energy 184, $1217-$ 1229. https://doi.org/10.1016/j.apenergy.2016.06.017

Prati, G., Albanesi, C., Pietrantoni, L., 2017. The interplay among environmental attitudes, proenvironmental behavior, social identity, and pro-environmental institutional climate. A longitudinal study. Environ. Educ. Res. 23, 176-191. https://doi.org/10.1080/13504622.2015.1118752

Robelia, B., Murphy, T., 2012. What do people know about key environmental issues? A review of environmental knowledge surveys. Environ. Educ. Res. 18, 299-321. https://doi.org/10.1080/13504622.2011.618288

Rodríguez-Barreiro, L.M., Fernández-Manzanal, R., Serra, L.M., Carrasquer, J., Murillo, M.B., Morales, M.J., Calvo, J.M., Del Valle, J., 2013. Approach to a causal model between attitudes and environmental behaviour. A graduate case study. J. Clean. Prod. 48, 116-125. https://doi.org/10.1016/j.jclepro.2012.09.029

Rodriguez-Sanchez, C., Schuitema, G., Claudy, M., Sancho-Esper, F., 2018. How trust and emotions influence policy acceptance: The case of the Irish water charges. Br. J. Soc. Psychol. 57, 610-629. https://doi.org/10.1111/bjso.12242 
Sarabia-Sanchez, F.J., Rodriguez-Sanchez, C., 2016. The role of credibility and negative feelings in comparative perceptual bias related to environmental hazards. J. Environ. Psychol. 47, 1-13. https://doi.org/10.1016/j.jenvp.2016.04.011

Shen, J., Saijo, T., 2008. Reexamining the relations between socio-demographic characteristics and individual environmental concern: Evidence from Shanghai data. J. Environ. Psychol. 28, 4250. https://doi.org/10.1016/j.jenvp.2007.10.003

Steg, L., Vlek, C., 2009. Encouraging pro-environmental behaviour: An integrative review and research agenda. J. Environ. Psychol. 29, 309-317. https://doi.org/10.1016/j.jenvp.2008.10.004

Stern, P.C., 2011. Contributions of psychology to limiting climate change. Am. Psychol. 66, 303314. https://doi.org/10.1037/a0023235

Sütterlin, B., Brunner, T.A., Siegrist, M., 2011. Who puts the most energy into energy conservation? A segmentation of energy consumers based on energy-related behavioral characteristics. Energy Policy 39, 8137-8152. https://doi.org/10.1016/j.enpol.2011.10.008

Tam, K.P., Chan, H.W., 2018. Generalized trust narrows the gap between environmental concern and pro-environmental behavior: Multilevel evidence. Glob. Environ. Chang. 48, 182-194. https://doi.org/10.1016/j.gloenvcha.2017.12.001

Thøgersen, J., 2004. A cognitive dissonance interpretation of consistencies and inconsistencies in environmentally responsible behavior. J. Environ. Psychol. 24, 93-103. https://doi.org/10.1016/S0272-4944(03)00039-2

Thøgersen, J., Ölander, F., 2003. Spillover of environment-friendly consumer behaviour. J. Environ. Psychol. 23, 225-236. https://doi.org/10.1016/S0272-4944(03)00018-5

United Nations, 2004. A more secure world: Our shared responsibility. https://doi.org/10.2307/20034356

Vicente-Molina, M.A., Fernández-Sainz, A., Izagirre-Olaizola, J., 2018. Does gender make a difference in pro-environmental behavior? The case of the Basque Country University students. J. Clean. Prod. 176, 89-98. https://doi.org/10.1016/j.jclepro.2017.12.079

Vicente-Molina, M.A., Fernández-Sáinz, A., Izagirre-Olaizola, J., 2013. Environmental knowledge and other variables affecting pro-environmental behaviour: Comparison of university students from emerging and advanced countries. J. Clean. Prod. 61, 130-138. https://doi.org/10.1016/j.jclepro.2013.05.015

Vining, J., Ebreo, A., 2002. Emerging theoretical and methodological perspectives on conservation behavior, in: R. Bechtel, \& A.C. (Ed.), New Handbook of Environmental Psychology. Wiley, New York, pp. 541-558. https://doi.org/10.1016/j.jenvp.2004.02.001

Von Borgstede, C., Andersson, M., Johnsson, F., 2013. Public attitudes to climate change and carbon mitigation-Implications for energy-associated behaviours. Energy Policy 57, 182-193. https://doi.org/10.1016/j.enpol.2013.01.051

Worldwatch Institute, 2013. State of the world 2013: Is sustainability still possible?

Zeithaml, V.A., 1988. Consumer perceptions of price, quality, and value: A means-end model and synthesis of evidence. J. Mark. 52, 2-22. https://doi.org/10.2307/1251446

Zelezny, L.C., Chua, P.P., Aldrich, C., 2000. Elaborating on gender differences in environmentalism. J. Soc. Issues 56, 443-457. https://doi.org/10.1111/0022-4537.00177 
Figure 1. Research Model

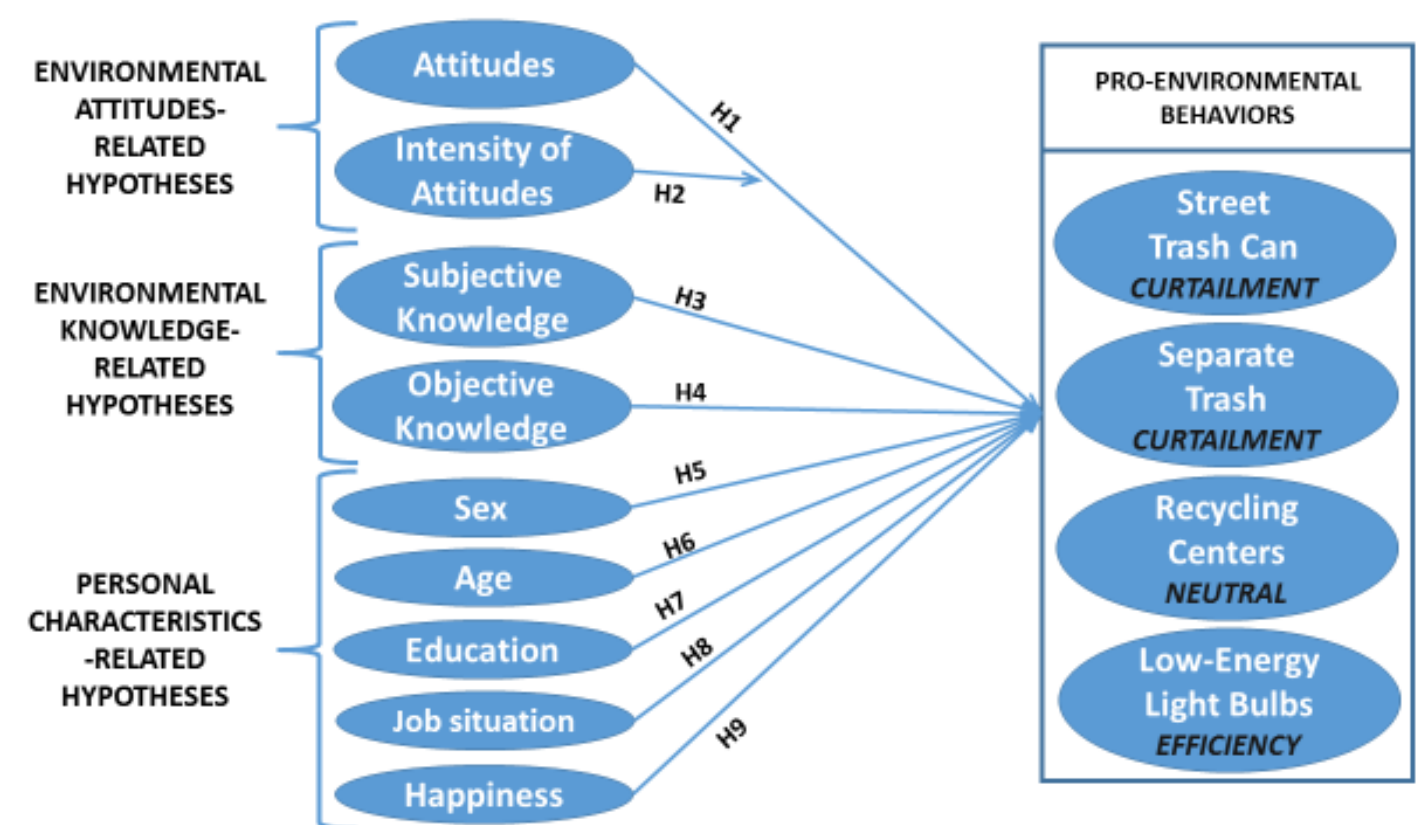


Table 1. Descriptive analysis of the environmental behavior index

\begin{tabular}{lccc}
\hline Behavior & $\mathrm{N}$ & $\mathrm{M}$ & $\mathrm{SD}$ \\
\hline Street trash cans & 2,460 & 0.784 & 0.412 \\
Separate trash & 2,461 & 0.718 & 0.45 \\
Low-energy light bulbs & 2,478 & 0.705 & 0.456 \\
Recycling centers & 2,429 & 0.737 & 0.441 \\
\hline
\end{tabular}

Table 2. Descriptive information of environmental attitudes and knowledge

\begin{tabular}{llccc}
\hline Variable & & $\mathrm{N}$ & $\mathrm{M}$ & $\mathrm{SD}$ \\
\hline Environmental attitudes & Low EA & 2,385 & 0.211 & 0.408 \\
& Moderate EA & 2,385 & 0.274 & 0.446 \\
& High EA & 2,385 & 0.514 & 0.500 \\
Subjective knowledge & Not informed & 2,478 & 0.070 & 0.255 \\
& Poorly informed & 2,478 & 0.450 & 0.498 \\
& Quite well informed & 2,478 & 0.415 & 0.493 \\
& Very well informed & 2,478 & 0.065 & 0.246 \\
Objective knowledge & No & 2,491 & 0.236 & 0.425 \\
& Yes & 2,491 & 0.764 & 0.425 \\
\hline
\end{tabular}

Table 2. Descriptive information of environmental attitudes and knowledge

\begin{tabular}{llc}
\hline Variable & & $\mathrm{M}$ \\
\hline Environmental attitudes & Low EA & 0.211 \\
& Moderate EA & 0.274 \\
& High EA & 0.514 \\
Subjective knowledge & Not informed & 0.07 \\
& Poorly informed & 0.45 \\
& Quite well informed & 0.415 \\
& Very well informed & 0.065 \\
Objective knowledge & No & 0.236 \\
& Yes & 0.764 \\
\hline
\end{tabular}


Table 3. Mixed effects logistic regressions

\begin{tabular}{|c|c|c|c|c|c|c|c|c|}
\hline \multirow{2}{*}{$\begin{array}{l}\text { Variable } \\
\text { Intercept }\end{array}$} & \multicolumn{2}{|c|}{ Street trash can } & \multicolumn{2}{|c|}{ Separate trash } & \multicolumn{2}{|c|}{ Recycling centers } & \multicolumn{2}{|c|}{ Low-energy light bulbs } \\
\hline & -1.178 & $* *$ & -0.953 & & -1.206 & $* *$ & -0.749 & \\
\hline & $(0.531)$ & & $(0.493)$ & & $(0.489)$ & & $(0.475)$ & \\
\hline \multirow[t]{2}{*}{ Moderate EA } & -0.019 & & 0.135 & & -0.112 & & -0.231 & \\
\hline & $(0.152)$ & & $(0.138)$ & & $(0.146)$ & & $(0.139)$ & \\
\hline \multirow{2}{*}{ High EA } & 0.621 & $* * *$ & 0.625 & $* * *$ & 0.18 & & 0.029 & \\
\hline & $(0.147)$ & & $(0.131)$ & & $(0.137)$ & & $(0.130)$ & \\
\hline \multirow[t]{2}{*}{ Poorly informed } & 0.550 & $* *$ & 0.380 & & 0.539 & $* *$ & -0.049 & \\
\hline & $(0.224)$ & & $(0.216)$ & & $(0.213)$ & & $(0.216)$ & \\
\hline \multirow[t]{2}{*}{ Quite well informed } & 0.998 & $* * *$ & 0.800 & $* * *$ & 0.889 & $* * *$ & 0.317 & \\
\hline & $(0.238)$ & & $(0.226)$ & & $(0.224)$ & & $(0.225)$ & \\
\hline \multirow[t]{2}{*}{ Very well informed } & 1.478 & $* * *$ & 1.095 & $* * *$ & 1.534 & $* * *$ & 0.861 & $* * *$ \\
\hline & $(0.354)$ & & $(0.309)$ & & $(0.337)$ & & $(0.315)$ & \\
\hline \multirow{2}{*}{ Paris Conference } & 0.147 & & 0.125 & & 0.200 & & 0.346 & $* * *$ \\
\hline & $(0.138)$ & & $(0.128)$ & & $(0.131)$ & & $(0.125)$ & \\
\hline \multirow[t]{2}{*}{ Male } & -0.224 & & -0.226 & $* *$ & -0.254 & $* *$ & -0.375 & $* * *$ \\
\hline & $(0.115)$ & & $(0.103)$ & & $(0.106)$ & & $(0.099)$ & \\
\hline \multirow[t]{2}{*}{ Age20 } & 0.390 & & 0.077 & & 0.415 & & 0.191 & \\
\hline & $(0.364)$ & & $(0.351)$ & & $(0.350)$ & & $(0.352)$ & \\
\hline \multirow[t]{2}{*}{ Age30 } & 0.432 & & 0.135 & & 0.755 & $* *$ & 0.599 & \\
\hline & $(0.386)$ & & $(0.371)$ & & $(0.372)$ & & $(0.373)$ & \\
\hline \multirow[t]{2}{*}{ Age40 } & 0.988 & $* *$ & 0.522 & & 1.094 & $* * *$ & 0.704 & \\
\hline & $(0.391)$ & & $(0.373)$ & & $(0.375)$ & & $(0.373)$ & \\
\hline \multirow[t]{2}{*}{ Age50 } & 1.378 & $* * *$ & 0.921 & $* *$ & 1.037 & $* * *$ & 0.464 & \\
\hline & $(0.401)$ & & $(0.380)$ & & $(0.378)$ & & $(0.376)$ & \\
\hline \multirow[t]{2}{*}{ Age60 } & 1.531 & $* * *$ & 1.269 & $* * *$ & 1.417 & $* * *$ & 0.757 & \\
\hline & $(0.432)$ & & $(0.409)$ & & $(0.407)$ & & $(0.398)$ & \\
\hline \multirow[t]{2}{*}{ Age70 } & 1.713 & $* * *$ & 1.145 & $* * *$ & 1.429 & $* * *$ & 0.568 & \\
\hline & $(0.470)$ & & $(0.436)$ & & $(0.436)$ & & $(0.422)$ & \\
\hline \multirow[t]{2}{*}{ Age80 } & 1.348 & $* * *$ & 1.129 & $* *$ & 0.620 & & 0.059 & \\
\hline & $(0.494)$ & & $(0.466)$ & & $(0.453)$ & & $(0.446)$ & \\
\hline \multirow[t]{2}{*}{ High school } & 0.374 & $* * *$ & 0.170 & & 0.320 & $* *$ & 0.343 & $* * *$ \\
\hline & $(0.140)$ & & $(0.124)$ & & $(0.129)$ & & $(0.122)$ & \\
\hline \multirow[t]{2}{*}{ University } & 0.557 & $* * *$ & 0.479 & $* * *$ & 0.553 & $* * *$ & 0.363 & $* *$ \\
\hline & $(0.176)$ & & $(0.155)$ & & $(0.159)$ & & $(0.145)$ & \\
\hline Unemployed & -0.137 & & -0.126 & & -0.119 & & -0.110 & \\
\hline & $(0.145)$ & & $(0.131)$ & & $(0.137)$ & & $(0.130)$ & \\
\hline Student & -0.204 & & -0.025 & & -0.396 & & -0.078 & \\
\hline & $(0.310)$ & & $(0.295)$ & & $(0.293)$ & & $(0.295)$ & \\
\hline Retired & -0.416 & & -0.403 & $* *$ & -0.411 & $* *$ & -0.254 & \\
\hline & $(0.219)$ & & $(0.194)$ & & $(0.193)$ & & $(0.175)$ & \\
\hline Happiness & 0.076 & $* *$ & 0.061 & $* *$ & 0.079 & $* *$ & 0.119 & $* * *$ \\
\hline & $(0.033)$ & & $(0.030)$ & & $(0.031)$ & & $(0.029)$ & \\
\hline $\operatorname{Var}(\text { Rand. Interc. })^{\mathrm{a}}$ & 0.507 & & 0.293 & & 0.175 & & 0.099 & \\
\hline LR test ${ }^{\mathrm{b}}$ & 61.6 & $* * *$ & 48.8 & $* * *$ & 15.4 & $* * *$ & 2.98 & \\
\hline $\mathrm{R}^{2}$ Cox-Snell & 0.222 & & 0.209 & & 0.201 & & 0.185 & \\
\hline $\mathrm{R}^{2}$ Nagelkerke & 0.324 & & 0.287 & & 0.280 & & 0.251 & \\
\hline
\end{tabular}

Notes:

${ }^{\mathrm{a}}$ Variance of random intercepts

${ }^{\mathrm{b}}$ LR test distributed as a chi-squared with one degree of freedom: $\mathrm{H}_{0}$ : Mixed effects logistic regression vs. $\mathrm{H}_{\mathrm{A}}$ : logistic regression.

$* *$ p-value $<0.05 . * * *$ p-value $<0.01$. 